BRAZIULIAN JOURNAL

OF MEDICAL AND BIOLOGICAL RESFARCH

www.bjournal.com.br
ISSN 0100-879X

Volume 44 (12) 1194-1298 December 2011

BIOMEDICAL SCIENCES

AND

CLINICAL INVESTIGATION

Braz J Med Biol Res, December 2011, Volume 44(12) 1269-1275

doi: 10.1590/S0100-879X2011007500149

Plasma von Willebrand factor as a predictor of survival in pulmonary arterial hypertension associated with congenital heart disease

A.A. Lopes, A.C. Barreto, N.Y. Maeda, C. Cícero, R.P.S. Soares, S.P. Bydlowski and S. Rich

The Brazilian Journal of Medical and Biological Research is partially financed by
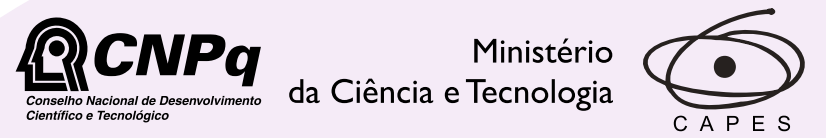

Ministério da Educação
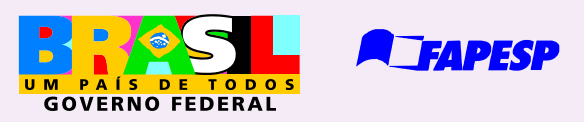

Institutional Sponsors
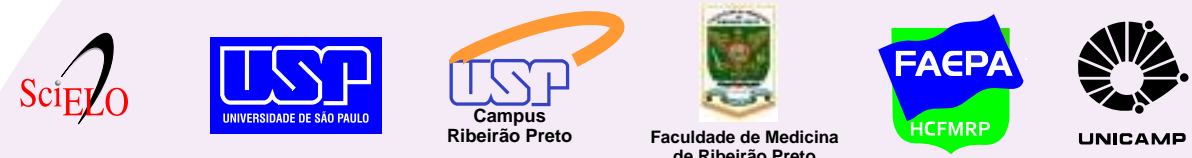

UNICAMP
Ф SHIMADZU

Explore High - Performance MS Orbitrap Technology In Proteomics \& Metabolomics

\section{analitica Thermo}




\title{
Plasma von Willebrand factor as a predictor of survival in pulmonary arterial hypertension associated with congenital heart disease
}

\author{
A.A. Lopes ${ }^{1}$, A.C. Barreto ${ }^{1}$, N.Y. Maeda², C. Cícero ${ }^{1}$, R.P.S. Soares ${ }^{2}$, \\ S.P. Bydlowski ${ }^{3}$ and S. Rich 4 \\ ${ }^{1}$ Instituto do Coração, Faculdade de Medicina, Universidade de São Paulo, São Paulo, SP, Brasil \\ ${ }^{2}$ Fundação Pró-Sangue Hemocentro de São Paulo, São Paulo, SP, Brasil \\ ${ }^{3}$ LIM-31, Faculdade de Medicina, Universidade de São Paulo, São Paulo, SP, Brasil \\ ${ }^{4}$ Department of Medicine, University of Chicago, Chicago, IL, USA
}

\begin{abstract}
Biomarkers have been identified for pulmonary arterial hypertension, but are less well defined for specific etiologies such as congenital heart disease-associated pulmonary arterial hypertension (CHDPAH). We measured plasma levels of eight microvascular dysfunction markers in $\mathrm{CHDPAH}$, and tested for associations with survival. A cohort of 46 inoperable $\mathrm{CHDPAH}$ patients (age 15.0 to 60.2 years, median 33.5 years, female:male 29:17) was prospectively followed for 0.7 to 4.0 years (median 3.6 years). Plasma levels of von Willebrand factor antigen (VWF:Ag), tissue plasminogen activator (t-PA) and its inhibitor (PAI-1), $\mathrm{P}$-selectin, reactive C-protein, tumor necrosis factor alpha, and interleukin- 6 and -10 were measured at baseline, and at 30, 90 , and 180 days in all subjects. Levels of six of the eight proteins were significantly increased in patients versus controls (13 to $106 \%$ increase, $P<0.003)$. Interleukin-10 level was 2.06 times normal $(P=0.0003$; Th2 cytokine response). Increased levels of four proteins (t-PA, PAI-1, P-selectin, and interleukin-6) correlated with disease severity indices $(P<0.05)$. Seven patients died during follow-up. An average VWF:Ag (mean of four determinations) above the level corresponding to the 95th percentile of controls $(139 \mathrm{U} / \mathrm{dL}$ ) was independently associated with a high risk of death (hazard ratio $=6.56,95 \% \mathrm{Cl}=1.46$ to $29.4, \mathrm{P}=$ 0.014). Thus, in CHDPAH, microvascular dysfunction appears to involve Th2 inflammatory response. Of the biomarkers studied, plasma vWF:Ag was independently associated with survival.
\end{abstract}

Key words: Pulmonary hypertension; Congenital heart disease; Eisenmenger syndrome; Endothelial dysfunction; von Willebrand factor; Th2 cytokine response

\section{Introduction}

There has been growing interest in the identification of biomarkers in pulmonary arterial hypertension (PAH). The most extensively analyzed marker is the cardiac hormone brain natriuretic peptide (BNP), either the whole molecule or its intact N-terminal-pro-fragment (NT-proBNP). Increased circulating levels of these peptides have been associated with a poor prognosis in pulmonary hypertension (1), as they are believed to reflect right ventricular dysfunction. In addition, serum uric acid levels correlate with the severity of idiopathic PAH and are associated with mortality (2), as is also the case for $\mathrm{PAH}$ due to the Eisenmenger syndrome
(3). The circulating levels of endothelin-1 (4) and D-dimer (5) have also been proposed as biomarkers in pulmonary hypertension.

We have shown (6) that increased circulating levels of von Willebrand factor antigen (VWF:Ag), a known marker of endothelial dysfunction, were associated with decreased short-term survival in "primary" and "secondary" (Eisenmenger syndrome) pulmonary hypertension. However, the small patient populations and the short follow-up time prevented us from performing a detailed survival analysis. Others, however, have recently confirmed that VWF:Ag is

Correspondence: A.A. Lopes, Unidade Clínica de Cardiologia Pediátrica e Cardiopatias Congênitas do Adulto, InCor, HC-FM-USP, Av. Dr. Eneas C. Aguiar, 44, 05403-000 São Paulo, SP, Brasil. Fax: +55-11-2661-5409. E-mail: aablopes@usp.br

Part of a Doctoral thesis presented by A.C. Barreto to the Departamento de Cardiologia, Faculdade de Medicina, Universidade de São Paulo, São Paulo, SP, Brasil.

Received February 11, 2011. Accepted October 18, 2011. Available online November 11, 2011. Published November $28,2011$. 
an independent predictor of survival (7) in PAH (idiopathic, familial or associated with anorexigen use). In the present study, we looked at eight circulating plasma proteins to characterize microvascular dysfunction in the specific setting of $\mathrm{PAH}$ associated with congenital heart disease and to determine if they reflected the severity of the disease. We measured plasma levels of VWF:Ag, tissue-type plasminogen activator (t-PA), plasminogen activator inhibitor 1 (PAl-1) and P-selectin to monitor endothelial dysfunction. We also measured plasma levels of reactive $C$-protein and interleukin-6 (IL-6) as nonspecific markers of inflammation, and tumor necrosis factor alpha (TNF- $\alpha$ ) and IL-10 as markers of Th1 and Th2 cytokine response, respectively. Additionally, we prospectively investigated possible associations between these biomarkers and survival over a period of 4 years. Demographic, functional and treatment-related variables were included in the analysis.

\section{Patients and Methods}

\section{Study population and design}

The patient population consisted of 46 patients from a previous study of 60 consecutive individuals with $\mathrm{PAH}$ who were randomly assigned to 6-month rosuvastatin or placebo treatment in order to investigate the effects of the statin on endothelial dysfunction markers (8). In the initial study, the first patient was enrolled in July 2005; in the present study, the follow-up was terminated in February 2010. In 46 patients (statin:placebo, 23:23), PAH was associated with uncorrected, inoperable congenital cardiac defects (Table 1). Of these, 18 were acyanotic, while 28 individuals had typical features of the Eisenmenger syndrome, with systemic oxygen saturation $<90 \%$. All patients were on chronic anticoagulant therapy with warfarin, and some of them were treated with oral vasodilator therapy for $\mathrm{PAH}$. Vasodilators were given to all functional class III patients, and some who were class II based on the life style and the degree of exercise-induced hypoxemia.

All patients had demographic data and functional parameters (functional class, distance walked in 6 min, systemic oxygen saturation, and noninvasive hemodynamics) recorded at baseline. Plasma levels of 4 endothelial dysfunction markers were determined at baseline, and 30, 90, and 180 days later during treatment (rosuvastatin versus placebo). Using additional plasma samples that were stored in parallel, we subsequently extended the biochemical analyses to include three cytokines, and C-reactive protein. Demographic and functional data obtained at patient entry in the first study, as well as results of all biochemical analyses, were used in the present study to define a general en- dothelial and inflammatory response for this group, and to identify factors that might be associated with an increased risk of death.

The study protocol was approved by the Scientific Committee of Instituto do Coração (SDC2613/05/033), and the Ethics Committee of Hospital das Clínicas (CAPPesq 380/05), Faculdade de Medicina, Universidade de São Paulo, São Paulo, SP, Brazil. Written informed consent was obtained from all patients (or their parents in case of adolescents) before inclusion in the study.

\section{Demographic, functional and treatment-related variables}

Patient age and gender were recorded at baseline. The functional class was graded according to the classification modified for pulmonary hypertension by the World Health Organization. The six-minute walk distance was determined according to a standardized protocol (9). Systemic oxygen saturation was measured by pulse oximetry, at rest and at the end of the six-minute walk. Pulmonary artery systolic and mean pressures were estimated noninvasively by Doppler echocardiography $(10,11)$. Catheterization data that confirmed the diagnosis of $\mathrm{PAH}$ and the congenital heart defect were obtained for all patients at different times prior to patient inclusion in the trial, and for this reason were not used in the analyses that were carried out in the study. The use of rosuvastatin during the first 6 months and the duration of vasodilator therapy (bosentan, sildenafil or a combination of both) were considered in the survival analysis.

\section{Biochemical analyses}

Proteins were measured by high-sensitivity enzymelinked immunosorbent assays. Commercial kits were purchased from R\&D Systems Inc., USA (P-selectin, TNF- $\alpha$, IL-6, and IL-10), Diagnostica Stago, France (VWF:Ag, t-PA and PAI-1), or American Diagnostica Inc., USA (C-reactive protein). The following results were obtained for each patient (and each biomarker): 1) baseline plasma level;

Table 1. Congenital cardiac anomalies of the patients studied.

\begin{tabular}{lc}
\hline Anomaly & No. of patients \\
\hline Ventricular septal defect & 19 \\
Atrial septal defect & 10 \\
Atrioventricular septal defect & 7 \\
Patent ductus arteriosus & 4 \\
Atrial and ventricular septal defects & 2 \\
Ventricular septal defect and patent ductus arteriosus & 1 \\
Double outlet right ventricle & 1 \\
Transposition of the great arteries with a ventricular septal defect & 1 \\
Single ventricle & 1 \\
Total & 46 \\
\hline
\end{tabular}


2) average level (mean of determinations performed at baseline and at 30, 90, and 180 days); 3) highest level of four determinations. Control plasmas were obtained from 30 healthy volunteers (consecutively selected blood donors or adolescents with innocent cardiac murmur) in the same age range as the patients. Blood donors were non-smokers, had no clinical history of systemic hypertension, diabetes, vascular diseases or stroke, and had no evidence of ongoing infections or disorders. In adolescents, the diagnosis of innocent cardiac murmur was established after screening echocardiography. For each protein, upper levels corresponding to the 90th and 95th percentiles of controls were determined and tested as cutoff values in the prediction of increased risk of death.

\section{Statistical analysis}

Comparisons between patients and controls or patient groups were performed by the non-parametric Mann-Whitney test. Correlations of protein levels with demographic and functional parameters were analyzed by calculating the Spearman correlation coefficient. Univariate and multivariable Cox regression models were used to investigate possible associations of the specified proteins with survival time. Plasma levels were analyzed both as continuous and as categorical variables (i.e., above versus below the level corresponding to the 90th and 95th percentiles of controls). Once a potential risk factor was identified, it was analyzed for the possible existence of confounders. When each potential confounder was added to the model, a > $20 \%$ change (decrease) in the hazard ratio associated with the risk factor was considered to indicate confounding. Kaplan-Meier survival curves were constructed and compared using the log-rank (Cox-Mantel) test. In all procedures, the level of significance was set at 0.05 .

\section{Results}

The demographic and functional data of 46 patients included in the study are summarized in Table 2. Twenty-one received vasodilator therapies for $\mathrm{PAH}$ (bosentan, sildenafil, or a combination of both, mean treatment duration of 2.25 years). During a follow-up of 0.7 to 4.0 years (median 3.6 years), 7 patients died, 5 of them with initial Eisenmenger syndrome presentation. A fatal outcome was associated with worsening of functional capacity, right ventricular failure and progressive hypoxemia. In 3 patients, progression of pulmonary arterial thrombosis (despite chronic use of warfarin) was considered as an important event associated with death. Two patients died suddenly. There were no deaths during the first 6 months of follow-up.

Baseline and average plasma levels of endothelial dysfunction markers and cytokines are shown in Table 3. Levels of six plasma proteins were significantly elevated in patients compared to controls. The predominant cytokine response was of the Th2 subtype, as suggested by the increased levels of IL-10 relative to TNF- $\alpha$. As shown in Table 4, altered plasma levels of four proteins correlated significantly with disease severity indices. Plasma VWF:Ag, reactive C-protein, TNF- $\alpha$, and IL-10 did not correlate significantly with any of the variables listed in Table 4. Furthermore, there was no correlations between protein levels and pulmonary artery systolic pressure or functional class.

A significant association was observed between the average plasma VWF:Ag level and survival. An average VWF:Ag above the 90th percentile of normal subjects $(135 \mathrm{U} / \mathrm{dL})$ was associated with increased risk of death $(P=0.0404)$, as was the level corresponding to the 95th percentile of controls $(139 \mathrm{U} / \mathrm{dL} ; \mathrm{P}=0.0140)$. Four of the 9 patients with an average VWF:Ag level higher than $139 \mathrm{U} /$ $\mathrm{dL}$ died within 2.75 years of follow-up. Neither the baseline nor the highest level of VWF:Ag correlated with survival. The highest value of 4 determinations seemed to be less specific, since it was $>139$ and $>135 \mathrm{U} / \mathrm{dL}$ in 19 and 24 patients, respectively (with the same 4 deaths in each situation). Survival curves for the different levels of VWF:Ag are shown in Figure 1. Plasma levels of other proteins did not correlate significantly with survival. No association with survival could be established when protein levels were analyzed as continuous variables.

The risk of death associated with an average VWF:Ag above the level corresponding to the 90th or 95th percentile of controls was high (respective hazard ratios of 4.79 , $95 \% \mathrm{Cl}=1.07-21.44$, and of $6.56,95 \% \mathrm{Cl}=1.46-29.40)$. As shown in Table 5, the hazard ratio related to increased VWF:Ag was not significantly reduced by the inclusion of any potential confounder in the model. None of the demographic, functional or treatment-related variables listed in Table 5 had a significant association with survival during the period of the study.

Table 2. Demographic and functional data of the patients studied $(\mathrm{N}=46)$.

\begin{tabular}{lc}
\hline Age (years) & $33.5(15.0-60.2)$ \\
Female:male & $29: 17$ \\
Acyanotic:Eisenmenger syndrome & $18: 28$ \\
Functional class (II:III) & $38: 8$ \\
$\mathrm{PAP}_{\text {systolic }}(\mathrm{mmHg})$ & $97 \pm 25$ \\
$\mathrm{PAP}_{\text {mean }}\left(\mathrm{mmHg}^{\mathrm{a}}\right.$ & $52 \pm 17$ \\
Resting $\mathrm{SpO}_{2}(\%)$ & $89(79-96)$ \\
6-min walk $\mathrm{SpO}_{2}(\%)$ & $71(31-94)$ \\
6-min walk distance $(\mathrm{m})$ & $402 \pm 112$ \\
Hematocrit $(\%)$ & $52(37-79)$ \\
\hline
\end{tabular}

Data are reported as means $\pm S D$, or median (range). PAP = pulmonary artery pressure estimated by Doppler-echocardiography;

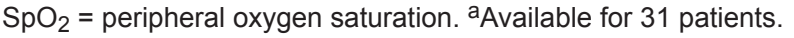


Table 3. Endothelial dysfunction markers and cytokines of patients $(N=46)$ and controls $(N=30)$.

\begin{tabular}{|c|c|c|c|c|c|c|c|c|c|}
\hline & $\begin{array}{c}\text { VWF:Ag } \\
\text { (U/dL) }\end{array}$ & $\begin{array}{c}\mathrm{t}-\mathrm{PA} \\
(\mathrm{ng} / \mathrm{mL})\end{array}$ & $\begin{array}{c}\text { PAl-1 } \\
\text { (ng/mL) }\end{array}$ & $\begin{array}{l}\text { P-selectin } \\
\text { (ng/mL) }\end{array}$ & $\begin{array}{c}\text { CRP } \\
(\mu \mathrm{g} / \mathrm{mL})\end{array}$ & $\begin{array}{c}\text { TNF- } \alpha \\
(p g / m L)\end{array}$ & $\begin{array}{c}\mathrm{IL}-6 \\
(\mathrm{pg} / \mathrm{mL})\end{array}$ & $\begin{array}{c}\mathrm{IL}-10 \\
(\mathrm{pg} / \mathrm{mL})\end{array}$ & $\begin{array}{l}\text { IL-10/ } \\
\text { TNF-C }\end{array}$ \\
\hline \multicolumn{10}{|l|}{ Controls } \\
\hline Median & 109 & 5.58 & 16.46 & 24.79 & 4.14 & 0.60 & 0.90 & 0.94 & 2.02 \\
\hline Lower & 62 & 2.87 & 5.23 & 8.82 & 0.67 & 0.08 & 0.29 & 0.003 & 0.04 \\
\hline Upper & 147 & 10.25 & 42.88 & 53.96 & 9.91 & 2.86 & 8.48 & 3.32 & 27.26 \\
\hline 90th percentile & 135 & 8.50 & 35.28 & 39.66 & 9.45 & 2.25 & 6.57 & 2.37 & 4.84 \\
\hline 95th percentile & 139 & 9.70 & 41.15 & 49.84 & 9.76 & 2.86 & 8.02 & 2.58 & 27.26 \\
\hline \multicolumn{10}{|l|}{ Patients (baseline) } \\
\hline Median & 123 & 7.82 & 24.53 & 43.12 & 6.50 & 0.70 & 1.44 & 1.94 & 3.18 \\
\hline Lower & 73 & 3.01 & 9.69 & 10.71 & 0.18 & 0.11 & 0.37 & 0.04 & 0.03 \\
\hline Upper & 177 & 23.93 & 134.71 & 136.94 & 11.80 & 5.61 & 10.58 & 11.88 & 20.13 \\
\hline \multicolumn{10}{|l|}{ Patients (average) ${ }^{a}$} \\
\hline Median & 125 & 7.72 & 25.25 & 42.70 & 6.04 & 0.84 & 1.80 & 1.89 & 2.92 \\
\hline Lower & 60 & 4.11 & 10.54 & 11.51 & 0.23 & 0.13 & 0.34 & 0.42 & 0.23 \\
\hline Upper & 197 & 21.67 & 127.55 & 138.12 & 13.00 & 5.93 & 8.67 & 6.24 & 31.73 \\
\hline $\mathrm{P}$ value (baseline vs controls) & 0.0025 & $<0.0001$ & $<0.0001$ & $<0.0001$ & 0.4961 & 0.3492 & 0.0006 & 0.0003 & 0.0414 \\
\hline$P$ value (average vs controls) & 0.0015 & $<0.0001$ & $<0.0001$ & $<0.0001$ & 0.5355 & 0.2244 & $<0.0001$ & 0.0002 & 0.0727 \\
\hline
\end{tabular}

VWF:Ag = plasma von Willebrand factor antigen; $\mathrm{t}-\mathrm{PA}=$ plasma tissue-type plasminogen activator; $\mathrm{PAI}-1$ = plasma plasminogen activator inhibitor 1 ; CRP = plasma C-reactive protein; TNF- $\alpha=$ plasma tumor necrosis factor alpha; IL-6 and IL-10 = plasma levels of interleukin- 6 and -10 , respectively; IL-10/TNF- $\alpha=$ plasma IL-10 relative to TNF- $\alpha$ concentration. aMean value of determinations performed at baseline, 30, 90, and 180 days. $P$ values obtained with the Mann-Whitney test.

Table 4. Endothelial dysfunction markers and cytokines versus demographic and functional parameters at baseline $(N=46)$.

\begin{tabular}{|c|c|c|c|c|c|c|c|}
\hline & Age & Gendera & $\begin{array}{c}\text { Clinical } \\
\text { presentation }\end{array}$ & Resting $\mathrm{SpO}_{2}$ & 6-min walk $\mathrm{SpO}_{2}$ & 6-min walk distance & Hematocrit \\
\hline t-PA & $\begin{array}{l}r_{S}=0.35 \\
P=0.0172\end{array}$ & NS & $P=0.0046$ & $\begin{array}{l}r_{S}=-0.29 \\
P=0.049\end{array}$ & NS & NS & $\begin{array}{l}r_{s}=0.49 \\
P=0.0005\end{array}$ \\
\hline PAl-1 & NS & NS & $P=0.0133$ & $\begin{array}{l}r_{s}=-0.31 \\
P=0.0345\end{array}$ & NS & $\begin{array}{l}r_{s}=-0.39 \\
P=0.0073\end{array}$ & NS \\
\hline P-selectin & NS & $P=0.004$ & $P=0.0069$ & NS & $\begin{array}{l}r_{s}=-0.31 \\
P=0.0379\end{array}$ & NS & $\begin{array}{l}r_{s}=0.61 \\
P<0.0001\end{array}$ \\
\hline IL-6 & NS & $P=0.0373$ & NS & NS & NS & NS & $\begin{array}{l}r_{s}=0.35 \\
P=0.0186\end{array}$ \\
\hline
\end{tabular}

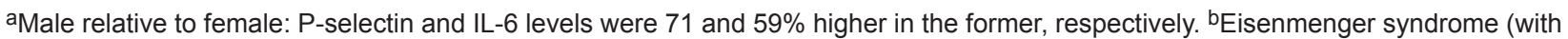
resting $\mathrm{SpO}_{2}<90 \%$ ), relative to acyanotic patients: t-PA, PAI-1, and P-selectin levels were 44, 60, and $64 \%$ higher in the former, respectively. $\mathrm{SpO}_{2}=$ peripheral oxygen saturation; $\mathrm{t}-\mathrm{PA}=$ plasma tissue-type plasminogen activator; $\mathrm{PAI}-1=$ plasma plasminogen activator inhibitor 1 ; IL-6 = interleukin-6. Correlations were tested by the Spearman correlation coefficient $\left(r_{s}\right)$. Comparisons between groups were performed by the Mann-Whitney test. NS = not significant.

\section{Discussion}

Microvascular dysfunction has been extensively studied in pulmonary hypertension (12). It includes decreased expression of prostacyclin and nitric oxide synthase and increased expression and secretion of vasoconstrictors (13-16). There is a shift toward a hypercoagulable state, with decreased expression of thrombomodulin (17) and increased production of tissue factor (18). There are increased plasma levels of proteins that are normally stored within endothelial Weibel-Palade bodies (von Willebrand factor, P-selectin and t-PA) $(6,17)$. Circulating endothelial cells and endothelial progenitor cells have been described in PAH (19), particularly in the congenital heart diseaseassociated form (20). Some of these markers seem to be related to the severity of the disease or change favorably in response to treatments $(17,20,21)$.

In the present study, specifically focused on PAH associated with congenital heart disease, circulating levels of four endothelial dysfunction markers and two cytokines were 

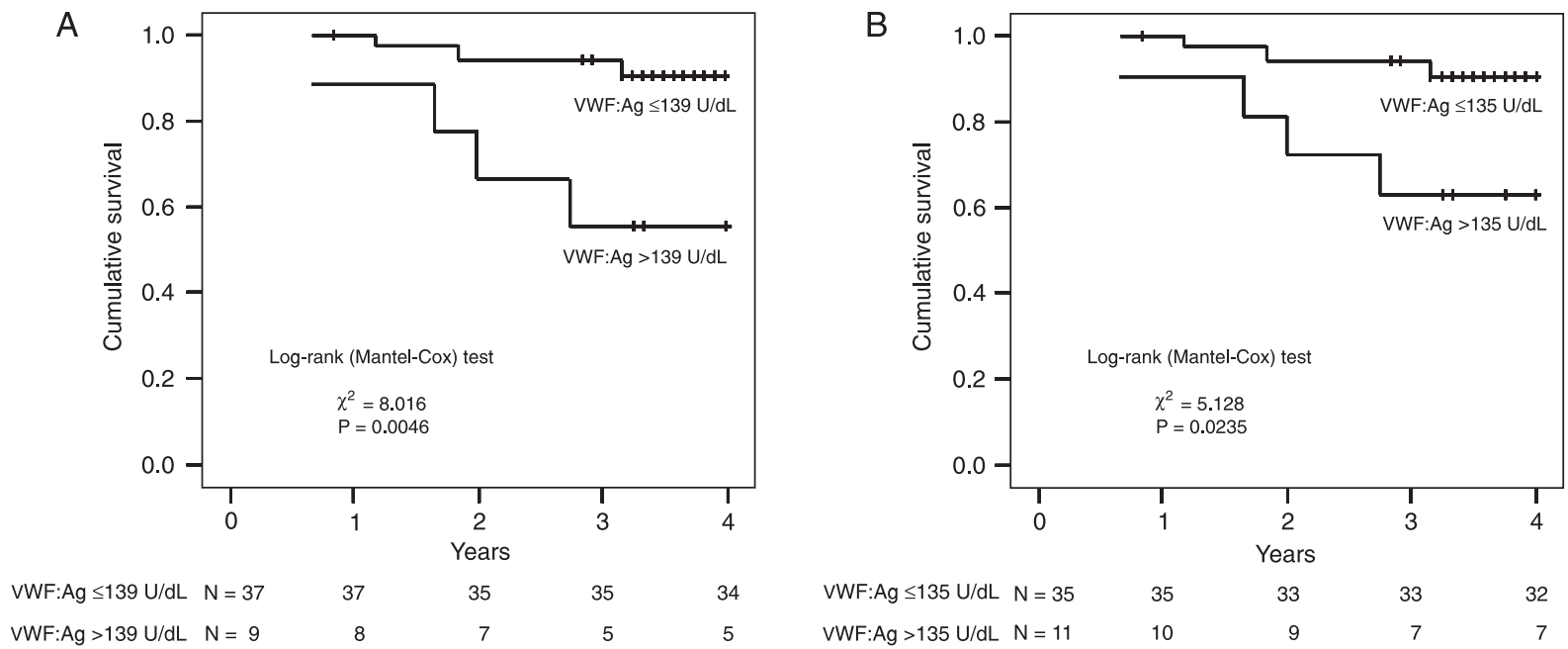

Figure 1. Kaplan-Meier survival curves for patients with pulmonary arterial hypertension associated with congenital heart disease according to plasma von Willebrand factor antigen (VWF:Ag). A, Patients with an average VWF:Ag (mean of determinations performed at baseline, 30, 90, and 180 days) above the 95th percentile of controls (in this case, $139 \mathrm{U} / \mathrm{dL}$ ) had a decreased life expectancy (mean survival of 3.01 years) compared with those at or below this limit (mean survival of 3.85 years). B, Patients with an average VWF:Ag above the 90th percentile of controls (in this case, $135 \mathrm{U} / \mathrm{dL}$ ) also had a shortened survival time (mean 3.19 years) compared with those at or below this level (mean survival 3.82 years). (+) represents censored cases.

elevated compared to normal subjects. The abnormalities in the plasma levels of four proteins correlated with clinical parameters of severity of the disease such as the magnitude of hypoxemia, erythrocytosis and decreased physical capacity. Of notice, hypoxia has been shown to induce endothelial PAI-1 gene expression and secretion of P-selectin and von Willebrand factor protein $(22,23)$. In this patient population, plasma VWF:Ag did not correlate with any of the functional parameters, but was identified as an independent predictor of survival. We also observed a mild but significant inflammatory response, which seemed to be predominantly Th2-cytokine related, as judged by the increased levels of IL-10 relative to TNF- $\alpha$. Taken together with previous reports in humans (24), this observation points toward a pathophysiological role of inflammation in PAH associated with congenital heart disease, similar to its role in idiopathic $\mathrm{PAH}$. Interestingly, in a recent report (25), a Th2 immune response was shown to induce pulmonary artery remodeling in an animal model.

Quantitative and qualitative abnormalities of circulating von Willebrand factor have been reported in PAH asso-
Table 5. Multivariate analysis of the association of plasma VWF:Ag with the risk of death $(\mathrm{N}=46)$ before and after addition of possible confounders.

\begin{tabular}{|c|c|c|c|c|}
\hline & $\mathrm{HR}(95 \% \mathrm{Cl})^{\mathrm{a}}$ & $\mathrm{P}$ & $\mathrm{HR}(95 \% \mathrm{Cl})^{\mathrm{b}}$ & $P$ \\
\hline Unadjusted & $4.79(1.07-21.44)$ & 0.040 & $6.56(1.46-29.40)$ & 0.014 \\
\hline \multicolumn{5}{|l|}{ Adjusted for: } \\
\hline Age & $4.23(0.86-20.70)$ & 0.075 & $5.94(1.23-28.75)$ & 0.027 \\
\hline Gender & $4.71(1.03-21.57)$ & 0.046 & $6.73(1.41-32.17)$ & 0.017 \\
\hline Clinical presentation ${ }^{c}$ & $4.67(1.01-21.68)$ & 0.049 & $6.39(1.41-28.95)$ & 0.016 \\
\hline Functional class & $5.06(1.12-22.91)$ & 0.035 & $6.61(1.47-29.79)$ & 0.014 \\
\hline Resting $\mathrm{SpO}_{2}$ & $4.51(1.00-20.37)$ & 0.050 & $5.75(1.26-26.34)$ & 0.024 \\
\hline 6-min walk $\mathrm{SpO}_{2}$ & $4.83(1.07-21.78)$ & 0.040 & $6.41(1.42-28.83)$ & 0.015 \\
\hline 6-min walk distance & $4.98(1.09-22.86)$ & 0.039 & $6.86(1.49-31.51)$ & 0.013 \\
\hline Hematocrit & $4.87(1.08-21.89)$ & 0.039 & $6.58(1.47-29.52)$ & 0.014 \\
\hline PAH advanced therapy ${ }^{d}$ & $4.70(1.04-21.13)$ & 0.044 & $6.88(1.52-31.16)$ & 0.012 \\
\hline Duration of treatment ${ }^{d}$ & $4.85(1.08-21.75)$ & 0.039 & $5.75(1.27-26.05)$ & 0.023 \\
\hline $\mathrm{PAP}_{\text {systolic }}$ & $4.88(1.09-21.89)$ & 0.038 & $8.45(1.72-41.43)$ & 0.009 \\
\hline Statine & $5.30(1.16-24.20)$ & 0.031 & $7.71(1.65-35.95)$ & 0.009 \\
\hline
\end{tabular}

aHR $(95 \% \mathrm{Cl})=$ hazard ratio $(95 \%$ confidence interval) associated with an average VWF:Ag (mean of determinations performed at baseline, 30, 90, and 180 days) above the level corresponding to the 90th percentile of controls. ${ }^{b} \mathrm{HR}(95 \% \mathrm{Cl})$ associated with an average VWF:Ag above the level corresponding to the 95th percentile of controls. "Eisenmenger syndrome (with resting $\mathrm{SpO}_{2}<90 \%$ ) present or absent. ${ }^{\mathrm{d}}$ Treatment for pulmonary arterial hypertension included bosentan, sildenafil or a combination of both. eUsed in the study from which the present cohort was derived (8). $\mathrm{SpO}_{2}=$ peripheral oxygen saturation; $\mathrm{PAH}=$ pulmonary arterial hypertension; PAP = pulmonary artery pressure estimated by Doppler-echocardiography. The search for possible confounders was carried out using bivariate Cox regression analysis. 
ciated with congenital heart defects (26). In our patients, increased plasma VWF:Ag levels (i.e., above the values corresponding to the 90th or 95th percentile in controls) were associated with worse outcome, a relationship that was not observed with the other proteins analyzed. This association was based on analyses that were performed with no missing data, and persisted after adjustments for multiple possible confounding factors. Thus, as observed in patients with $\mathrm{PAH}$ of other etiologies (7), our preliminary observations suggest that plasma VWF:Ag may be a predictor of prognosis in the congenital heart disease-associated form of the disease. It is important to note that neither the result of a single VWF:Ag determination (at baseline) nor the highest level obtained over six months of observation correlated significantly with survival. Von Willebrand factor is an acute-phase reactant, and its level may vary and can become transiently elevated in a number of acute inflammatory and infectious conditions $(27,28)$. Therefore, in the specific setting of $\mathrm{PAH}$ associated with congenital heart disease, persistently elevated VWF:Ag levels (as indicated by increased mean value of replicate observations) seem to be necessary for a "high-risk" status to be characterized. Thus, at least four determinations over a 6-month period may be required. How levels of biomarkers vary over time in patients is largely unknown and needs to be considered in future studies. In normal subjects, a persistent elevation of plasma VWF:Ag is not expected to occur if there are no ongoing vascular, thrombotic or inflammatory disorders. This was the case for controls in the present study. Although it would be desirable to have sequential determinations in controls as well (their absence being a limitation of the study), in practice, this approach has not been used in longitudinal studies (7).

Plasma VWF:Ag is a predictor of prognosis in several acute and chronic disorders (29-32). One may speculate that thrombosis is the link between increased infectious VWF:Ag and poor outcome in $\mathrm{PAH}$. As a powerful vascular growth factor, thrombin may serve as an important substrate for vascular proliferation (33). In the present study, pulmonary arterial thrombosis was observed in three of the seven patients who subsequently died. Alternatively, it is possible that the amount of circulating von Willebrand factor protein reflects the magnitude of other endotheliumrelated biological events that are themselves determinants of progression of the disease $(23,34-39)$.

Regarding the impact of treatment on survival, in a recent study on adults with Eisenmenger syndrome (40), both the functional class and the use of advanced therapies for $\mathrm{PAH}$ significantly influenced survival. In our study, survival was not influenced by the functional status, the use of specific drugs or the duration of treatments. Differences between the studies may be related to the characteristics of patient populations. The majority of our patients were only mildly symptomatic (38 patients in class II), and 18 subjects did not have the full picture of the Eisenmenger syndrome.

Microvascular dysfunction is present in PAH associated with congenital heart disease, indicating an increased inflammatory mechanisms in which the Th2 cytokine response plays a role. Plasma levels of microvascular dysfunction markers correlate with clinical indices of disease severity in these patients. Our data also suggest that in these patients, a sustained increase in plasma VWF:Ag level is indicative of a poor prognosis. Further studies of larger populations of patients with $\mathrm{PAH}$ are warranted. These findings suggest that therapies that target a reversal of the prothrombotic tendency of the pulmonary circulation may be beneficial.

\section{Acknowledgments}

Research supported by FAPESP (\#05/50320-5).

\section{References}

1. Blyth KG, Groenning BA, Mark PB, Martin TN, Foster JE, Steedman T, et al. NT-proBNP can be used to detect right ventricular systolic dysfunction in pulmonary hypertension. Eur Respir J 2007; 29: 737-744.

2. Nagaya N, Uematsu M, Satoh T, Kyotani S, Sakamaki F, Nakanishi N, et al. Serum uric acid levels correlate with the severity and the mortality of primary pulmonary hypertension. Am J Respir Crit Care Med 1999; 160: 487-492.

3. Oya H, Nagaya N, Satoh T, Sakamaki F, Kyotani S, Fujita M, et al. Haemodynamic correlates and prognostic significance of serum uric acid in adult patients with Eisenmenger syndrome. Heart 2000; 84: 53-58.

4. Rubens C, Ewert R, Halank M, Wensel R, Orzechowski HD, Schultheiss HP, et al. Big endothelin-1 and endothelin-1 plasma levels are correlated with the severity of primary pulmonary hypertension. Chest 2001; 120: 1562-1569.

5. Shitrit D, Bendayan D, Bar-Gil-Shitrit A, Huerta M, Rudensky $B$, Fink $G$, et al. Significance of a plasma D-dimer test in patients with primary pulmonary hypertension. Chest 2002; 122: 1674-1678.

6. Lopes AA, Maeda NY, Goncalves RC, Bydlowski SP. Endothelial cell dysfunction correlates differentially with survival in primary and secondary pulmonary hypertension. Am Heart J 2000; 139: 618-623.

7. Kawut SM, Horn EM, Berekashvili KK, Widlitz AC, Rosenzweig EB, Barst RJ. von Willebrand factor independently predicts long-term survival in patients with pulmonary arterial hypertension. Chest 2005; 128: 2355-2362.

8. Barreto AC, Maeda NY, Soares RP, Cicero C, Lopes AA. Rosuvastatin and vascular dysfunction markers in pulmonary arterial hypertension: a placebo-controlled study. Braz J Med Biol Res 2008; 41: 657-663.

9. ATS statement: guidelines for the six-minute walk test. $A m \mathrm{~J}$ Respir Crit Care Med 2002; 166: 111-117.

10. Masuyama T, Kodama K, Kitabatake A, Sato H, Nanto S, Inoue M. Continuous-wave Doppler echocardiographic 
detection of pulmonary regurgitation and its application to noninvasive estimation of pulmonary artery pressure. CircuIation 1986; 74: 484-492.

11. Borgeson DD, Seward JB, Miller FA Jr, Oh JK, Tajik AJ. Frequency of Doppler measurable pulmonary artery pressures. J Am Soc Echocardiogr 1996; 9: 832-837.

12. Budhiraja R, Tuder RM, Hassoun PM. Endothelial dysfunction in pulmonary hypertension. Circulation 2004; 109: 159-165.

13. Christman BW, McPherson CD, Newman JH, King GA, Bernard GR, Groves BM, et al. An imbalance between the excretion of thromboxane and prostacyclin metabolites in pulmonary hypertension. N Engl J Med 1992; 327: 70-75.

14. Tuder RM, Cool CD, Geraci MW, Wang J, Abman SH, Wright $\mathrm{L}$, et al. Prostacyclin synthase expression is decreased in lungs from patients with severe pulmonary hypertension. $\mathrm{Am}$ J Respir Crit Care Med 1999; 159: 1925-1932.

15. Giaid A, Saleh D. Reduced expression of endothelial nitric oxide synthase in the lungs of patients with pulmonary hypertension. N Engl J Med 1995; 333: 214-221.

16. Giaid A, Yanagisawa M, Langleben D, Michel RP, Levy R, Shennib $\mathrm{H}$, et al. Expression of endothelin-1 in the lungs of patients with pulmonary hypertension. N Engl J Med 1993; 328: 1732-1739.

17. Sakamaki F, Kyotani S, Nagaya N, Sato N, Oya H, Satoh T, et al. Increased plasma P-selectin and decreased thrombomodulin in pulmonary arterial hypertension were improved by continuous prostacyclin therapy. Circulation 2000; 102: 2720-2725.

18. White RJ, Meoli DF, Swarthout RF, Kallop DY, Galaria II, Harvey JL, et al. Plexiform-like lesions and increased tissue factor expression in a rat model of severe pulmonary arterial hypertension. Am J Physiol Lung Cell Mol Physiol 2007; 293: L583-L590.

19. Bull TM, Golpon H, Hebbel RP, Solovey A, Cool CD, Tuder $\mathrm{RM}$, et al. Circulating endothelial cells in pulmonary hypertension. Thromb Haemost 2003; 90: 698-703.

20. Diller GP, van Eijl S, Okonko DO, Howard LS, Ali O, Thum T, et al. Circulating endothelial progenitor cells in patients with Eisenmenger syndrome and idiopathic pulmonary arterial hypertension. Circulation 2008; 117: 3020-3030.

21. Friedman R, Mears JG, Barst RJ. Continuous infusion of prostacyclin normalizes plasma markers of endothelial cell injury and platelet aggregation in primary pulmonary hypertension. Circulation 1997; 96: 2782-2784.

22. Uchiyama T, Kurabayashi M, Ohyama Y, Utsugi T, Akuzawa $\mathrm{N}$, Sato $\mathrm{M}$, et al. Hypoxia induces transcription of the plasminogen activator inhibitor-1 gene through genistein-sensitive tyrosine kinase pathways in vascular endothelial cells. Arterioscler Thromb Vasc Biol 2000; 20: 1155-1161.

23. Pinsky DJ, Naka Y, Liao H, Oz MC, Wagner DD, Mayadas $\mathrm{TN}$, et al. Hypoxia-induced exocytosis of endothelial cell Weibel-Palade bodies. A mechanism for rapid neutrophil recruitment after cardiac preservation. J Clin Invest 1996; 97: 493-500.

24. Pinto RF, Higuchi ML, Aiello VD. Decreased numbers of T-lymphocytes and predominance of recently recruited macrophages in the walls of peripheral pulmonary arteries from 26 patients with pulmonary hypertension secondary to congenital cardiac shunts. Cardiovasc Pathol 2004; 13: 268-275.

25. Daley E, Emson C, Guignabert C, de Waal MR, Louten J, Kurup VP, et al. Pulmonary arterial remodeling induced by a
Th2 immune response. J Exp Med 2008; 205: 361-372.

26. Rabinovitch M, Andrew M, Thom H, Trusler GA, Williams WG, Rowe RD, et al. Abnormal endothelial factor VIII associated with pulmonary hypertension and congenital heart defects. Circulation 1987; 76: 1043-1052.

27. Rubin DB, Wiener-Kronish JP, Murray JF, Green DR, Turner $\mathrm{J}$, Luce JM, et al. Elevated von Willebrand factor antigen is an early plasma predictor of acute lung injury in nonpulmonary sepsis syndrome. J Clin Invest 1990; 86: 474-480.

28. Takahashi H, Ito S, Hanano M, Wada K, Niwano H, Seki $Y$, et al. Circulating thrombomodulin as a novel endothelial cell marker: comparison of its behavior with von Willebrand factor and tissue-type plasminogen activator. Am J Hematol 1992; 41: 32-39.

29. Folsom AR, Wu KK, Rosamond WD, Sharrett AR, Chambless LE. Prospective study of hemostatic factors and incidence of coronary heart disease: the Atherosclerosis Risk in Communities (ARIC) Study. Circulation 1997; 96: 11021108.

30. Morange PE, Simon C, Alessi MC, Luc G, Arveiler D, Ferrieres $\mathrm{J}$, et al. Endothelial cell markers and the risk of coronary heart disease: the Prospective Epidemiological Study of Myocardial Infarction (PRIME) study. Circulation 2004; 109: 1343-1348.

31. Tsai AW, Cushman M, Rosamond WD, Heckbert SR, Tracy $\mathrm{RP}$, Aleksic N, et al. Coagulation factors, inflammation markers, and venous thromboembolism: the longitudinal investigation of thromboembolism etiology (LITE). Am J Med 2002; 113: 636-642.

32. Ware LB, Conner ER, Matthay MA. von Willebrand factor antigen is an independent marker of poor outcome in patients with early acute lung injury. Crit Care Med 2001; 29: 23252331.

33. Gorlach A, BelAiba RS, Hess J, Kietzmann T. Thrombin activates the p21-activated kinase in pulmonary artery smooth muscle cells. Role in tissue factor expression. Thromb Haemost 2005; 93: 1168-1175.

34. Zavoico GB, Ewenstein BM, Schafer Al, Pober JS. IL-1 and related cytokines enhance thrombin-stimulated PGI2 production in cultured endothelial cells without affecting thrombin-stimulated von Willebrand factor secretion or platelet-activating factor biosynthesis. J Immunol 1989; 142: 3993-3999.

35. Wagner DD, Bonfanti R. von Willebrand factor and the endothelium. Mayo Clin Proc 1991; 66: 621-627.

36. Ribes JA, Francis CW, Wagner DD. Fibrin induces release of von Willebrand factor from endothelial cells. J Clin Invest 1987; 79: 117-123.

37. Hattori R, Hamilton KK, McEver RP, Sims PJ. Complement C5b-9 stimulates von Willebrand factor secretion from human endothelium. Circulation 1987; 78 (Suppl): II-117 (Abstract).

38. Paleolog EM, Crossman DC, McVey JH, Pearson JD. Differential regulation by cytokines of constitutive and stimulated secretion of von Willebrand factor from endothelial cells. Blood 1990; 75: 688-695.

39. Penny WF, Weinstein M, Salzman EW, Ware JA. Correlation of circulating von Willebrand factor levels with cardiovascular hemodynamics. Circulation 1991; 83: 1630-1636.

40. Dimopoulos K, Inuzuka R, Goletto S, Giannakoulas G, Swan L, Wort SJ, et al. Improved survival among patients with Eisenmenger syndrome receiving advanced therapy for pulmonary arterial hypertension. Circulation 2010; 121: 20-25. 